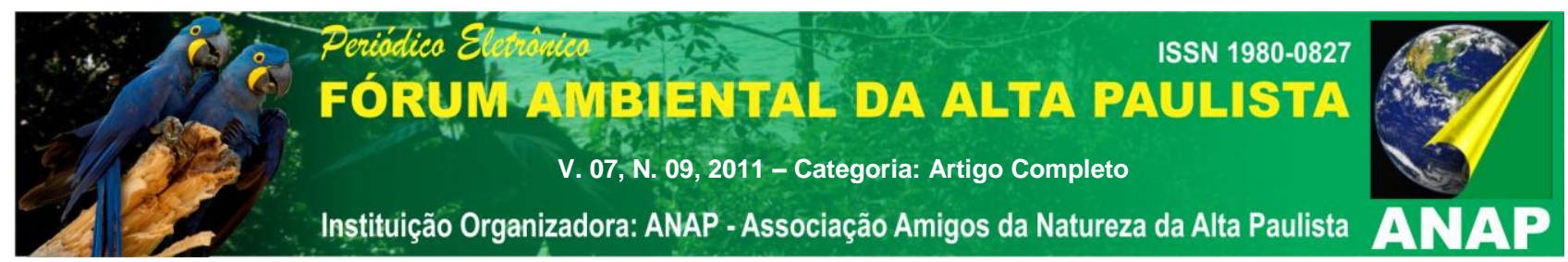

\title{
PROJETO RONDON: AÇÕES E REFLEXÕES SOBRE O PLANEJAMENTO TURÍSTICO NO MUNICÍPIO DE PARAÍSO DO SUL-RS
}

\author{
Silvana Kloster ${ }^{1}$ \\ Mario Cezar Lopes ${ }^{2}$
}

Resumo: O objetivo do artigo é apresentar as ações realizadas pelo Projeto Rondon no Município de Paraíso do Sul-RS referentes ao planejamento turístico. As ações foram realizadas juntamente com a participação da comunidade local por meio de oficinas de Conscientização Turística, Geoconservação e Cartografia Participativa e Inventariação Turística. Descreve-se o objeto de análise, sua formação territorial regional destacando o turismo como possível ação para o desenvolvimento territorial através do reconhecimento da identidade territorial e do planejamento participativo e por fim as ações e resultados obtidos.

Palavras chave: Paraíso do Sul-RS, Projeto Rondon, turismo, desenvolvimento territorial.

\section{APRESENTAÇÃO}

Entre as diversas ações desempenhadas pelo Projeto Rondon pelo País, está o desenvolvimento de ações voltadas às comunidades locais. O presente artigo relata a participação da UEPG (Universidade Estadual de Ponta Grossa) formada por uma equipe composta por estudantes e professores com o objetivo de auxiliar o Município de Paraíso do Sul-RS no planejamento de ações ligadas às atividades de turismo.

\footnotetext{
${ }^{1}$ Bacharel em Turismo e Mestranda em Gestão do Território pela Universidade Estadual de Ponta Grossa silkloster@hotmail.com

${ }^{2}$ Professor de Geografia pela Universidade Estadual de Ponta Grossa mclopes@uepg.br
} 


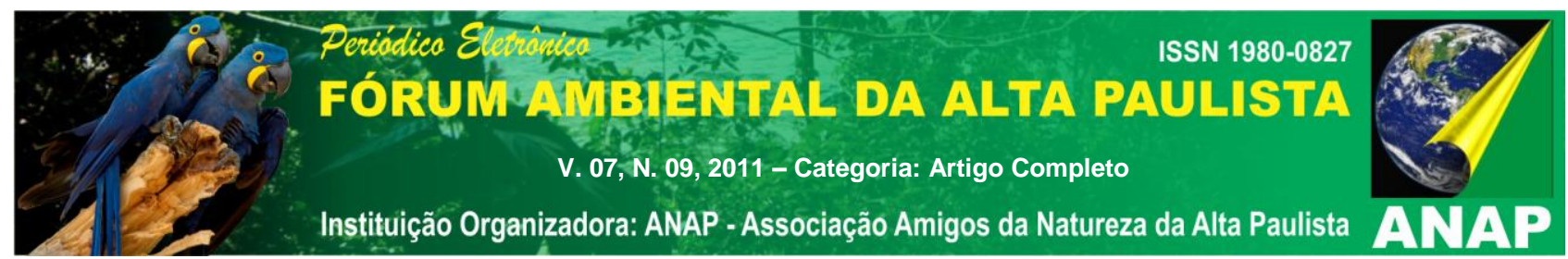

Inicia-se com a descrição do Projeto Rondon, sua história e o envolvimento da UEPG e suas ações dentro do Projeto. Na sequência descreve-se o Município de Paraíso do Sul-RS, como uma cidade típica rural, e a formação histórico territorial da região.

Demonstrar-se-á que o turismo pode servir como uma possível ação para o desenvolvimento territorial, mas que o Município precisa reconhecer sua identidade local como produto para o turismo ligando-se aos elementos, sejam material ou imaterial, únicos pertencentes ao território.

Para realização das ações do Projeto Rondon foi necessário conhecer a realidade do Município, tendo como objetivo, o planejamento participativo da comunidade.

As ações realizadas foram: as oficinas de Conscientização Turística por meio do método ZOOP e de Geoconservação e Cartografia e a Inventariação Turística levando a população a participar de todo o processo de planejamento das ações que deverão ser realizadas para o pleno êxito da inserção da atividade de turismo no Município e seu envolvimento com o entorno.

Através do reconhecimento da identidade territorial e a melhoria, em alguns aspectos, de elementos que servirão como base para o desenvolvimento turístico é hoje, o desafio do município de Paraíso do Sul.

\section{1- O Projeto Rondon}

O Projeto Rondon hoje é coordenado pelo Ministério da Defesa em parceria com mais oito ministérios, entre eles os Ministérios da Educação e Saúde. Promove a verdadeira extensão universitária das Instituições de Ensino Superior mobilizando a juventude, de maneira voluntária, a promover a cidadania, os direitos humanos e o desenvolvimento local sustentável com ações nas comunidades socialmente vulneráveis de todo o Brasil.

O nome é uma homenagem ao bandeirante do século XX, o Marechal Cândido Mariano da Silva Rondon. Seu idealizador é o professor Wilson Choeri da antiga UEG (Universidade Estadual de Guanabara, hoje UERJ). 


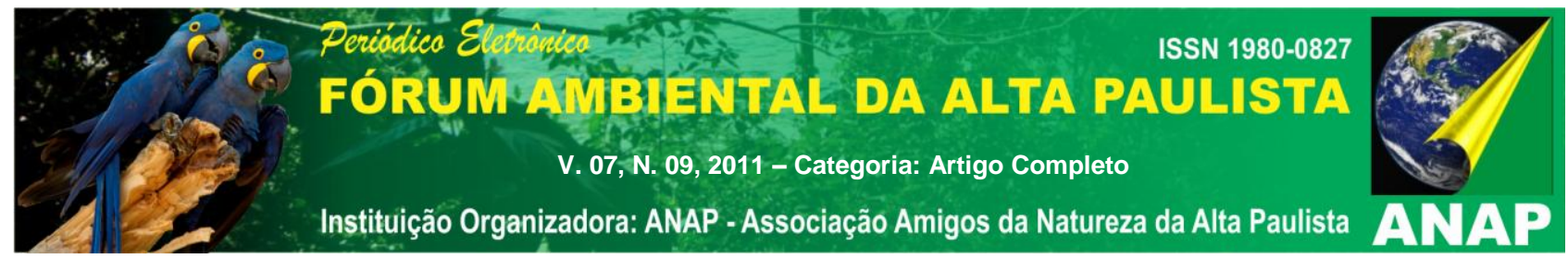

O Projeto Rondon teve início em julho de 1967, sob a coordenação do Ministério do Interior, com uma participação de 30 universitários da UEG, da UFF (Universidade Federal Fluminense) e da PUC/RJ (Pontifícia Universidade Católica do Rio de Janeiro) juntamente com o professor Omir Fontoura em ações no Território de Rondônia, hoje Estado de Rondônia.

Entre os anos de 1967 a 1987, o Projeto mobilizou cerca de 350 mil estudantes de todo o país.

Em 1990 foi criado a ONG Associação Nacional dos Rondonistas, associação civil do direito privado, apartidário e sem fins lucrativos. Em 2001 o nome e a logomarca do Projeto foram registrados no INPI (Instituto Nacional de Propriedade Industrial) e em 2006 foi assinado o acordo de cooperação com o Ministério da Defesa e da Educação.

A Universidade Estadual de Ponta Grossa, Instituição de ensino superior, localizada no Município de Ponta Grossa-PR, já participou de diversas expedições do Projeto Rondon pelas regiões brasileiras desde a década de 60 e em Julho de 2009, realizou ações nas áreas de saúde, direitos humanos, educação e cultura no Município de Paraíso do Sul - RS, juntamente com a ESALQ (Escola Superior de Agricultura Luiz de Queiróz) escola esta, localizada na cidade de Piracicaba - SP.

$\mathrm{Na}$ ocasião, as duas instituições realizaram cursos, oficinas e reuniões sobre as principais necessidades para melhoria da qualidade de vida na comunidade local. Dentre as ações desenvolvidas a área de Turismo foi a mais destacada por parte dos administradores municipais, mas, a menos trabalhada, pois a equipe não contava com alunos do Turismo, fato este que originou em junho de 2011 uma Operação Retorno ao Município de Paraíso do Sul, com uma equipe formada por acadêmicos do Turismo e Geografia, para ações específicas na Área do Turismo Regional e Local.

\section{2- O Município de Paraíso do Sul-RS: Reflexões sobre a atividade turística no seu entorno}

O município de Paraíso do Sul localiza-se ás margens da RST 287, Km 189, na região central do Estado do Rio Grande do Sul a aproximadamente $190 \mathrm{~km}$ de Porto Alegre. Foi emancipado em 12 de maio de 1988 a partir da união de dois distritos de Cachoeira do Sul: Paraíso do Sul e Rincão da Porta, criando o Município de Paraíso do 


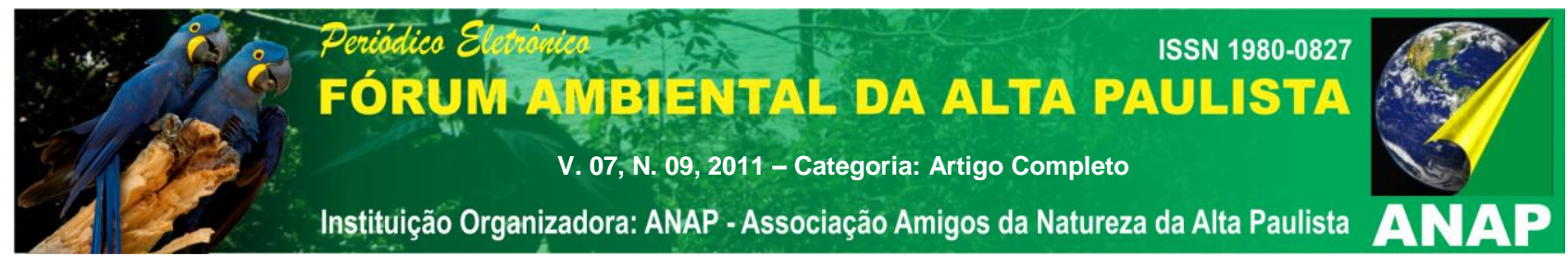

Sul, ficando a sede do Município onde era Rincão da Porta, e onde era Paraíso do Sul ficou denominado Vila Paraíso. Sua população é de aproximadamente 7.336 habitantes ocupando uma área de $342,45 \mathrm{~km}^{2}$

Fica próximo aos Municípios de Agudo, Cerro Branco, Cachoeira do Sul, Faxinal do Soturno e Dona Francisca.

É uma cidade tipicamente rural formada quase que exclusivamente por descendentes germânicos luteranos. A economia é voltada para o plantio de arroz em casca, fumo em folha seca, milho e soja em grãos.

A formação histórico territorial da região inicia-se a partir de duas colônias: Santo Ângelo de colonização alemã (atuais municípios de Agudo, Paraíso do Sul e Cerro Branco) e Quarta Colônia de colonização italiana (atuais municípios de Cachoeira do Sul, D. Francisca, Faxinal do Soturno, Nova Palma, Ivorá, Silveira Martins, Santa Maria).

Os municípios da Quarta Colônia reuniram-se para formação de um roteiro turístico que inclui o Município de Agudo, pertencente à Colônia Santo Ângelo, mas, que acabou inserindo-se ao roteiro devido a sua organização interna e pelo fato de Santo Ângelo não possuir um projeto de desenvolvimento turístico. Ou seja, a Quarta Colônia saiu na frente no planejamento da atividade turística. Essas cidades oferecem como atrativo as belezas naturais, as igrejas, eventos locais, a gastronomia e o artesanato.

As cidades vizinhas a Paraíso do Sul, envolvidas com a atividade turística, estão ligadas entre si por meio de redes de articulações e pontos e redes entre os grupos de interesse turístico (hotéis, restaurantes, atrativos locais). Segundo Haesbaert (2002) o termo rede contribui para compreendermos essas articulações entre diferentes territorialidades bem como suas estruturações internas.

Por meio das redes de relações entre os grupos e entre grupos de outros territórios, a comunidade e a demanda turística estão em constante movimento, influenciando os atores envolvidos, ocasionando a troca de culturas. Essa influência é perceptível ao visitarmos as cidades vizinhas e depois a cidade de Paraíso do Sul-RS, onde se vê que a cidade não possui o mesmo fluxo econômico e social que as outras cidades, parecendo isolada e estagnada ao tempo.

A necessidade de unir os territórios em prol do desenvolvimento regional de determinada atividade, como no caso do turismo é de crucial importância para que os mesmos tenham força econômica e projeção fora do espaço onde estão localizados. 


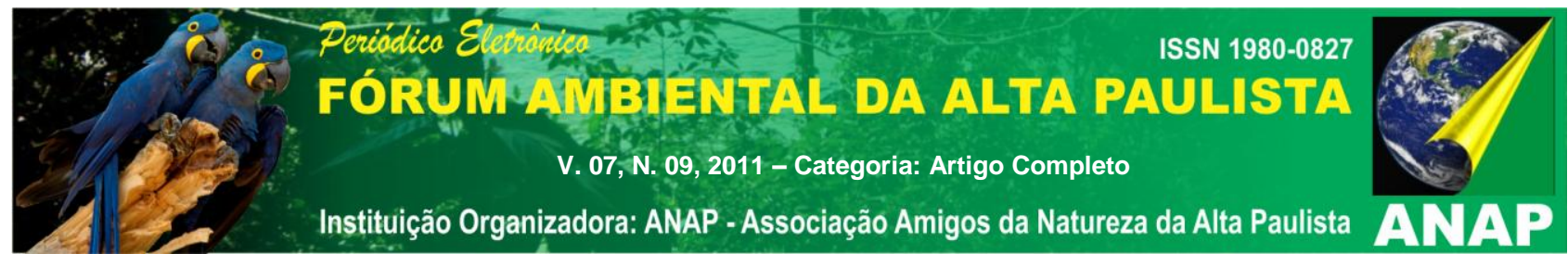

Para Veiga (2002), a recomposição dos territórios significa a necessidade de novas formas de governança que rompam com métodos políticos-administrativos já existentes superando as antigas estruturas de poder local, buscando a articulação e a cooperação, promovendo a "intercomunidade" entre as microrregiões. (VEIGA, 2002, p. 38).

Ao perceber que a região está articulada politicamente, recebendo visitantes e recursos financeiros para o turismo, Paraíso do Sul-RS está disposto a se preparar para a atividade turística e se unir aos demais Municípios, para fazer parte também, desse movimento pelo desenvolvimento regional.

\section{3- Turismo como possível ação para o desenvolvimento territorial}

Para o planejamento da atividade de turismo é necessário conhecer o potencial que servirá como identidade territorial do espaço. A construção do território se dá a partir da articulação de duas principais dimensões: uma ligada ao material, à esfera político-econômica e a outra, mais imaterial, ligada à esfera da cultura e do conjunto de símbolos e valores compartilhados por um grupo social. (HAESBAERT \& LIMONAD, 2007, p. 49). Interagindo com a visão do autor, podesse afirmar que a dimensão da esfera político-econômica está ligada ao material, aos recursos específicos, como a existência de determinados produtos ou recursos naturais únicos. Na esfera cultural, relaciona-se ao modo de vida, modo de produzir, como a forma e o saber fazer.

Desenvolver turisticamente Paraíso do Sul-RS é unir os elementos ligados a territorialidade, o material e o imaterial, elementos únicos que distinguem os potenciais representativos da cultura local e transformá-los em produtos de comercialização turística. Para melhor compreensão do termo cultura, recorre-se a WARNIER (2000, p. 23), segundo o qual, a cultura:

(...) é singular, geograficamente ou socialmente localizada, objeto de expressão discursiva em uma língua dada, fator de identificação dos grupos e dos indivíduos e de diferenciação diante dos outros, bem como fator de orientação dos atores, uns em relação aos outros e em relação ao seu meio. Toda cultura é transmitida por tradições reformuladas em função do contexto histórico. 


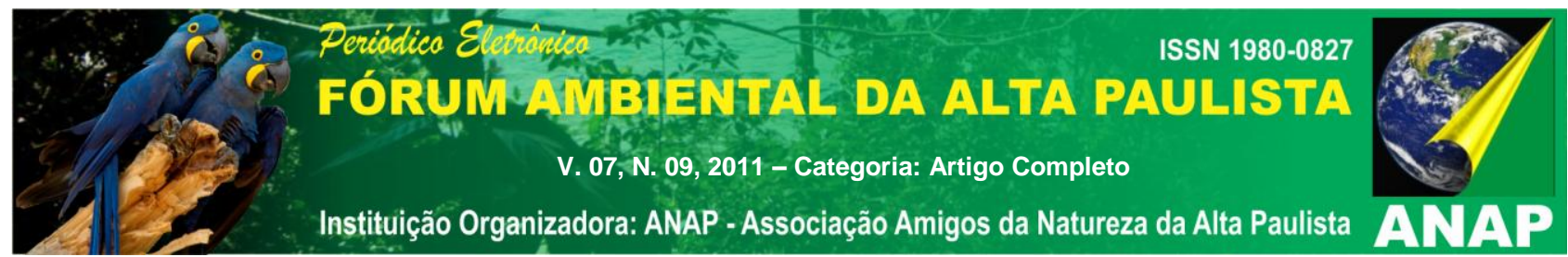

Nesse sentido, o território desperta o sentimento de pertencimento, de valorização do cultural, derivada das atividades espaciais de grupos pertencentes ao território, importante matéria prima para o turismo.

Relacionando o turismo, em especial, o rural, com o desenvolvimento econômico, o mesmo poderá oferecer soluções parciais para os problemas relacionados às políticas agrícolas falhas, por meio de ações como: a criação de um mercado para os produtos agrícolas tradicionais, produtos excedentes e outros cuja tendência é desaparecer, como o artesanato, por exemplo; a possibilidade da criação de novas fontes de renda em espaços já produtivos e a atração de investimentos financeiros externos para melhoria de infraestrutura, investimento em conhecimentos e de informações. (RUCHMANN in ALMEIDA; FROEHLICH; RIEDL, 2000, p. 65).

O crescimento da demanda por produtos diferenciados e com identidade territorial é uma tendência mundial. Produtos como os agroecológicos, orgânicos e social e ecologicamente corretos estão ganhando um mercado de consumidores cada vez mais exigente. (DENARDIN; SULZBACH in SAQUET e SANTOS, 2010).

Para o conhecimento dos bens materiais e imateriais existentes em Paraíso do Sul, a sequencia do artigo demonstra de que maneira ouve a interação com a comunidade local e quais foram os resultados obtidos visando o planejamento turístico participativo.

\section{4- Envolvimento da Comunidade no Planejamento: Ações e Resultados}

Durante os anos de 2009 a 2011, a prefeitura de Paraíso do Sul-RS manteve contato com a UEPG e juntamente com os professores dessa instituição, organizaram a viagem de retorno ao Município.

O Prof. Mário Lopes, coordenador do projeto Rondon pela UEPG, escalou uma equipe com dez pessoas entre estudantes de Turismo e Geografia, pós-graduandos e professores para retornar ao Município e realizar um diagnóstico descrevendo os principais passos para o desenvolvimento turístico de Paraíso do Sul-RS.(foto 01

Para a inserção da atividade turística, é necessária a participação coletiva da comunidade, visto que o planejamento deve ser construído com base no interesse dos moradores locais e não algo imposto por interesses externos, sem o conhecimento da 


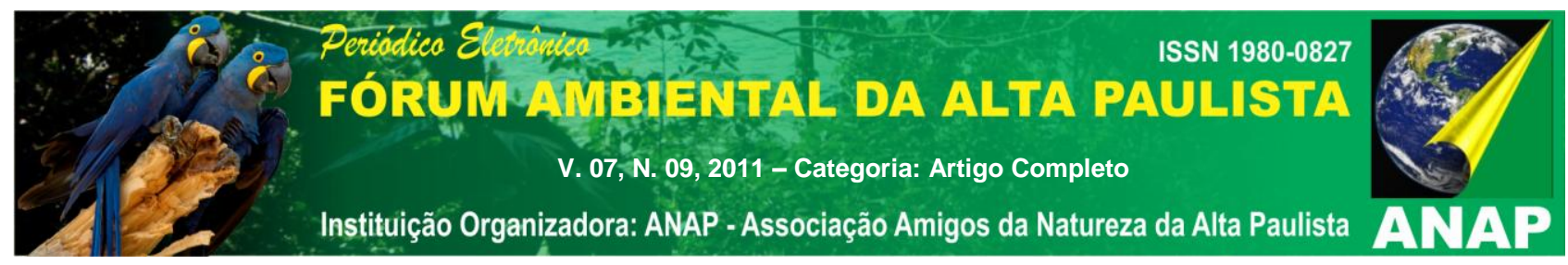

realidade e da potencialidade turística que só quem convive no espaço conhece.

Diante disso, para melhor interação com a comunidade, a equipe realizou algumas ações como: oficinas de Turismo e de Geoconservação e Cartografia Participativa e o início da inventariação turística. Essas oficinas contaram com a participação de pessoas da comunidade e representantes das secretarias municipais. O objetivo principal foi medir o grau de conhecimento da comunidade sobre o turismo como atividade econômica, promovendo a reflexão da identidade territorial do Município e as possibilidades de inserção na atividade turística.

A primeira oficina realizada foi de Conscientização Turística. O modelo é o mesmo utilizado pelo Ministério do Turismo através do PNMT (Programa Nacional de Municipalização do Turismo) nos anos de 1994 a 2003. Eram conduzidas por um moderador e o método utilizado é o ZOOP - Planejamento de Projetos Orientados por Objetos. Esse método, por meio da introdução de recomendações e técnicas, facilita a visualização das perguntas e respostas utilizando painéis e tarjetas, facilitando a mobilização do conhecimento, estimulando o debate entre os participantes e criando um ambiente agradável de cooperação. Essa forma de oficina visava à conscientização, à sensibilização, ao estímulo e à capacitação dos vários monitores municipais para que despertassem sobre a importância e a dimensão do turismo como gerador de emprego e renda e como um meio de preservação e a manutenção dos patrimônios ambiental, histórico e cultural, com a participação da comunidade local.

Em Paraíso do Sul, essa atividade contou com a participação de 30 (trinta) pessoas da comunidade que foram divididas em quatro grupos de trabalho. Cada grupo era responsável em responder determinadas perguntas feitas por um moderador da nossa equipe. Ao final de cada debate, por meio da construção coletiva eram expostas as respostas.

Para o início, perguntou-se o que significa Turismo e o grupo respondeu:

Apresentação da sua região, do seu lugar;

Autoconhecimento do seu potencial atrativo;

Valorização das suas riquezas;

Receber o turista com qualificação;

Sustentável economicamente;

Despertar o município para novas atividades; 


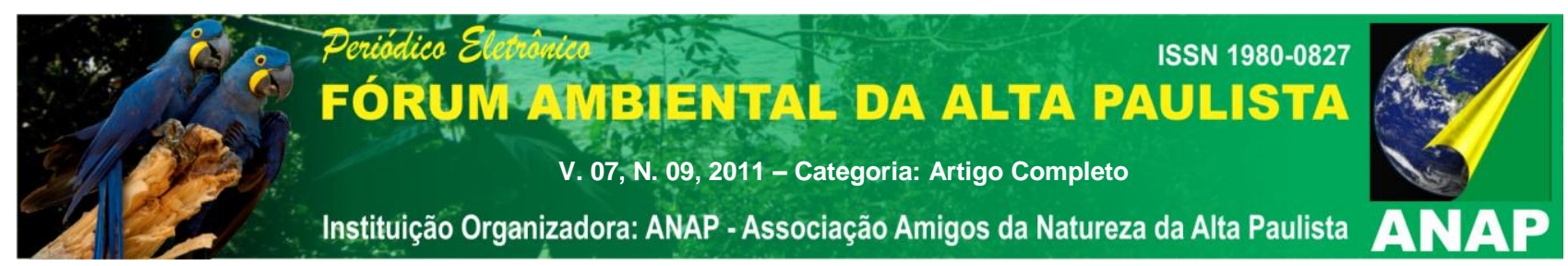

(resposta dos 30 membros)

$\mathrm{Na}$ sequencia perguntou-se sobre os pontos positivos do turismo e o grupo colocou que:

Através do turismo as regiões conseguem se desenvolver economicamente e gerar divisas. Com o turismo vem à conscientização e preservação das comunidades e assim uma maior divulgação dos atrativos turísticos. (resposta grupo 1)

Já os pontos negativos:

- Falta de segurança que pode causar graves problemas, como por exemplo, em uma trilha ecológica, onde algum turista pode perder-se se não for orientado corretamente ou risco a integridade física do turista em passeio que requer equipamentos de segurança;

- A falta de organização pode prejudicar a imagem de alguns pontos turísticos e até do próprio município;

- Aumento do lixo;

- Aumento da violência;

- Poluição Sonora (aumento do barulho);

- Aumento do esgoto;

- Impacto no meio ambiente.

(resposta do grupo 2)

Quando perguntado sobre: qual é o potencial turístico da cidade de Paraíso do SulRS? A resposta foi:

Paraíso do Sul possui um potencial turístico vasto como: Exploração de trilhas através dos pontos turísticos do nosso município como o poço verde, o morro solitário, açude das garças, pau-a-pique, incluindo a cerca de pedra. (grupo 4)

Sobre o que precisa ser melhorado no Município:

Criar (descobrir) uma identidade turística

Organizar-se estruturalmente;

Melhoria no transporte, alimentação e hospedagem;

Organização e investimento $(\mathrm{R} \$)$. (grupo 1) 


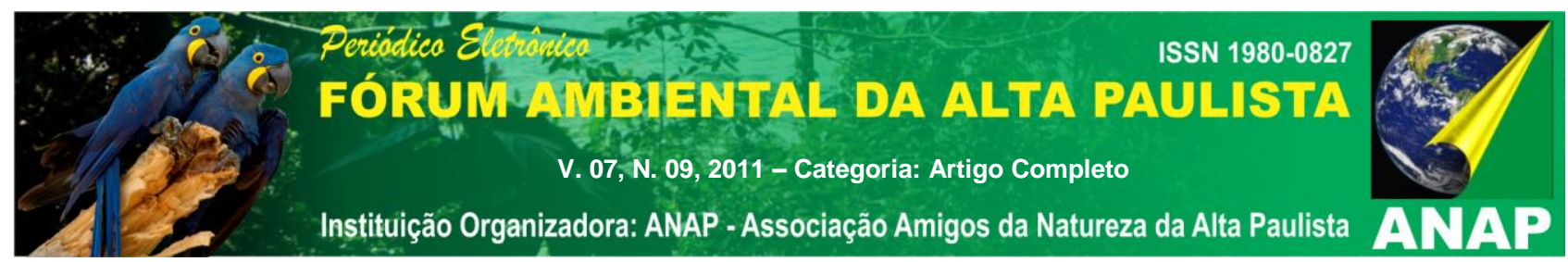

Por meio da construção coletiva das respostas, pode-se perceber que a comunidade local reconhece o turismo como uma atividade e que poderá auxiliar na divulgação e no desenvolvimento econômico, mas que vários são os aspectos que precisam ser melhorados no Município para que o mesmo esteja apto a receber turistas.

Para que o trabalho tenha segmento após as ações do Projeto Rondon, o grupo participante foi orientado sobre a importância do Município possuir um Conselho Municipal de Turismo (COMTUR) e um Plano de Desenvolvimento Local para o Turismo. Foram levados vários exemplos de cidades que se desenvolveram turisticamente e que tem como base a formação dos Conselhos de Turismo.

O Conselho é formado por membros da comunidade local com interesse em realizar ações para o desenvolvimento da atividade turística. É composto por membros da iniciativa pública (secretarias municipais) e privada (hotéis, restaurante, transporte). Os membros do COMTUR têm o papel de planejar e coordenar ações para o turismo, incentivando a comunidade a divulgar a imagem turística, promovendo a conservação do Patrimônio Natural e Cultural local.

$\mathrm{Na}$ visão do grupo, Paraíso do Sul-RS necessita ter um Conselho Municipal de Turismo para:

- Para levantar as diretrizes básicas da construção ou conservação do turismo no município;

- Interação do turismo com os demais órgãos públicos;

- Incentivar o turismo no município;

- Conservação de prédios antigos e histórico;

- Dar continuidade aos projetos, independente de partido político. Levar o nome do município, em troca de um bem comum a todos;

- Elaborar planos e metas a serem alcançados a curto, longo e médio prazo. (resposta do grupo geral)

Uma das atribuições do COMTUR, de acordo com grupo, é o de formar um estatuto para assegurar a continuidade do Conselho Municipal de Turismo. As demais são: "buscar recursos, planejar, organizar e executar ações para a consolidação do turismo local". (resposta do grupo geral)

Os principais entraves que poderão ocorrer para a criação do COMTUR, de acordo com os moradores "é a falta de apoio do poder público, privado e da própria comunidade". 


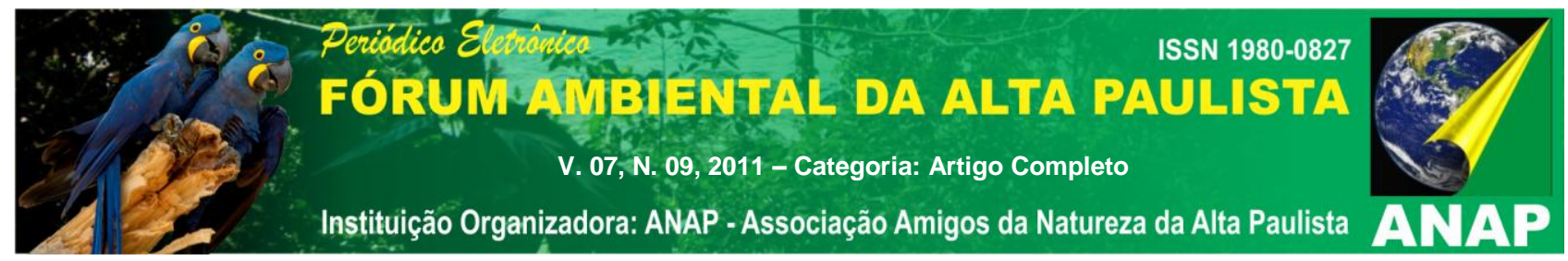

(resposta do grupo geral)

O grupo acredita que poderá envolver a comunidade no desenvolvimento do Plano Municipal de Turismo através de palestras e reuniões, convidando a comunidade para participar trazendo ideias e opiniões através de encontros mensais. Nesses encontros serão avaliados os pontos fortes e os que devem ser melhorados.

Um aspecto abordado na Oficina e que necessita ser considerado é o do comércio local que é pouco representativo para a economia do Município, o que faz com que seus moradores realizem o chamado movimento pendular comprando produtos e trabalhando na cidade de Agudo, cidade mais próxima a Paraíso do Sul. O comércio de Agudo tornase atrativo e mais desenvolvido que o comércio de Paraíso do Sul, mantendo o pensamento "a grama do vizinho é sempre mais verde que a minha" nos moradores de Paraíso do Sul, ou seja, os produtos comercializados em Agudo são melhores e mais variados que o de Paraíso do Sul. Isso faz com que o comércio não tenha alternativa senão, oferecer preços maiores para tentar se manter economicamente perdendo clientes para o comércio do Município vizinho.

O grupo participante alegou que "é melhor comprar na cidade vizinha não só pelos preços, mas porque aproveitam a ocasião para passear e ver "coisas" bonitas em Agudo". (resposta do grupo geral) Os próprios moradores reconhecem que Paraíso do Sul possui potencial para atrair visitantes, mas que esse potencial precisa ser transformado em produto turístico, assim como as cidades vizinhas estão fazendo com seus atrativos, utilizando o próprio comércio como atrativo.

Os moradores sabem da importância econômica, social e cultural que a atividade turística pode trazer ao Município porque estão percebendo que os municípios ao seu entorno estão recebendo turistas e se autovalorizando como cidade turística como é o caso de Agudo, Dona Francisca e Vale Vêneto.

Essas cidades se organizaram para o turismo recebendo um número significativo de turistas com tendência de crescimento e hoje, ainda possuem poucos hotéis e restaurantes, boas vias de acesso e placas de sinalização turística, além de bons roteiros aliado a lindas paisagens para os visitantes.

Além da baixa autoestima do comércio local, outro problema que preocupa os moradores do Município é o pouco grau de instrução e o quadro atual do cultivo do fumo em função do baixo preço pago pela indústria fumageira aos produtores locais, sob a 


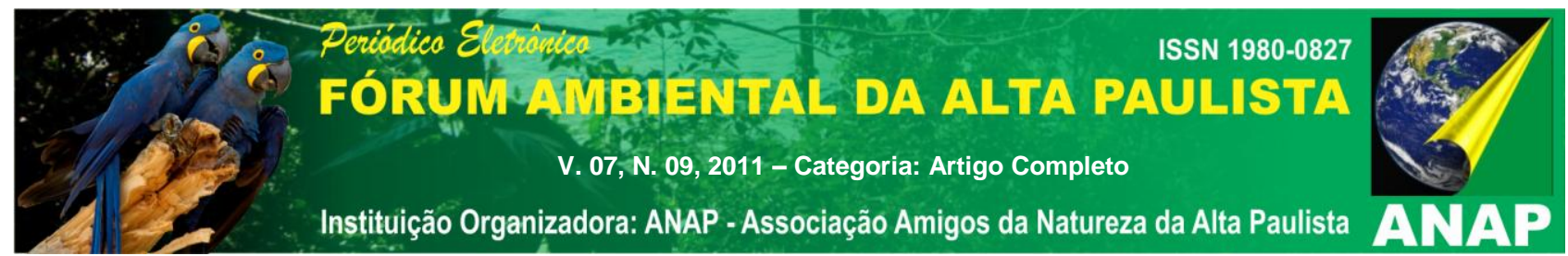

alegação da falta de qualidade do produto. Aliado a isso, existe toda a pressão da legislação anti-tabagismo e de preservação ambiental que, sob o olhar politicamente correto, torna o cultivo do fumo, um fator negativo para o município, principalmente, quando se pensa em explorar a atividade turística.

Paraíso do Sul apresenta pontos positivos para o desenvolvimento da atividade turística, estando o seu maior potencial na área rural com atrativos naturais como, a cascata Poço Verde e o Morro Solitário e aspectos culturais típicos como a cultura germânica e as construções antigas, além do excelente clima de hospitalidade típico dos moradores gaúchos.

Juntamente com a Oficina de Turismo, foram realizadas duas ações: a primeira foi o início da inventariação turística de Paraíso do Sul-RS (conforme modelo do Ministério do Turismo) com diagnóstico prévio. O Inventário da Oferta Turística de acordo com o Ministério do Turismo (2011):

Consiste no levantamento, identificação e registro dos atrativos turísticos, dos serviços e equipamentos turísticos e da infraestrutura de apoio ao turismo como instrumento base de informações para fins de planejamento, gestão e promoção da atividade turística, possibilitando a definição de prioridades para os recursos disponíveis e o incentivo ao turismo sustentável.

(disponível no http://www.inventario.turismo.gov.br/invtur/jsp/sobre_invtur/)

Outra ação realizada no Município foi a Oficina de Geoconservação e Cartografia Participativa com a formulação de um mapa das principais potencialidades existentes no Município.

De acordo com o diagnóstico realizado, para que a atividade de turismo ocorra é necessário avançar em alguns aspectos do Município como: saneamento básico, já que Paraíso do Sul ainda não conta com coleta de esgoto. O Município só é bom para o turista se for bom para o morador local e as prefeituras precisam cuidar melhor da sua população principalmente porque o saneamento básico está ligado à prevenção de doenças.

Além disso, é necessária uma coleta seletiva do lixo produzido na cidade aliado a educação ambiental. Em tempos contemporâneos, o lixo produzido não deve ser tratado como algo descartável, resíduo depositado na natureza e sim como fonte de renda para 


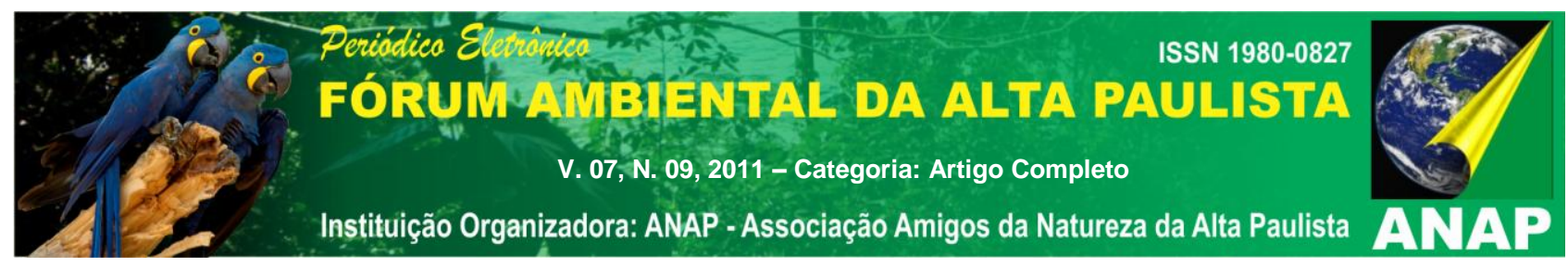

muitas famílias por meio da reciclagem.

Outro aspecto a ser observado é a criação do Serviço de Vigilância Sanitária atuante no Município. Existem muitas propriedades rurais ligadas à agroindústria, na produção de queijos, geleias, vinhos e outros produtos alimentícios. O problema é que esses produtos não seguem um padrão de embalagens, sem data de validade e sem normas de refrigeração e estocagem, o que ocasiona um problema para quem tem a intenção de vender produtos aos turistas. Não é por falta de interesse da comunidade em geral em agir de maneira correta na manipulação de alimentos, mas sim há a falta de conhecimento sobre o assunto.

É necessário melhoria das estradas rurais uma vez que o Município concentra a maior parte da população no meio rural além dos principais atrativos. A falta de manutenção nas estradas é um problema que ocorre em grande parte dos municípios brasileiros e que deve ser mais bem visto pelo poder público.

Outras observações são a criação de Legislação ambiental para a proteção das áreas naturais e de Legislação para a preservação do patrimônio histórico e cultural. O Município conta com prédios do início do século XX e alguns imóveis não passam por restauração e/ou estão sendo derrubados.

Ao final dos trabalhos, o resultado das Oficinas serviu como material de apoio para a elaboração de um documento entregue ao prefeito municipal descrevendo os passos para o desenvolvimento turístico.

Entre os principais passos descritos no documento está: a criação de um departamento específico para o turismo, visto que no Município, o turismo está ligado ao Departamento de Esportes; criação do COMTUR (Conselho Municipal de Turismo); conclusão da inventariação turística; melhoria das vias de acesso no meio rural, programas de valorização do pequeno produtor rural; criação de um Serviço de Inspeção Municipal (SIM) atuante; revitalização do Centro de Comercialização de Produtos Coloniais; criação de um Centro de Informações Turísticas e de material informativo; melhoria na sinalização turística; a criação de uma Casa da Memória em homenagem aos primeiro imigrantes na região e de um calendário de eventos do Município.

\section{5- Considerações finais}




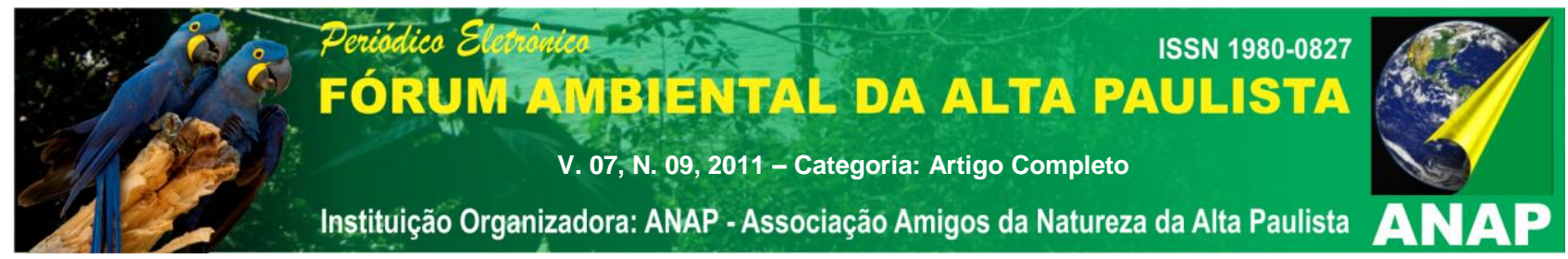

A busca de novas experiências acadêmicas faz com que muitos estudantes busquem inserção em projetos de pesquisa que aliam o conhecimento científico às práticas e conhecimentos populares auxiliando na melhoria da qualidade de vida e no desenvolvimento social e econômico de diversas regiões do Brasil, como é o caso do Projeto Rondon.

O Projeto Rondon trouxe como experiência, o sentimento de colaboração e de pertencimento de uma instituição de ensino como a UEPG, possibilitando aliar a teoria adquirida nos cursos superiores, à prática vivenciada pelas comunidades existentes em regiões distantes, reconhecendo em nós mesmos, a capacidade de auxiliá-las nos dando a oportunidade de conhecer realidades diferentes ao que vivenciamos no nosso cotidiano como foi o caso do Município de Paraíso do Sul -RS.

Paraíso do Sul-RS tem capacidade de programar e desenvolver ações voltadas ao turismo porque possui dois fatores importantes para o início da atividade turística: o interesse pelo turismo de seus governantes e da região onde está inserido e a capacidade de acolhimento e carisma que a comunidade local possui.

Dentro do planejamento turístico, devemos levantar quais as ações que serão necessárias para a inserção da atividade dentro de um Município. No caso de Paraíso do Sul, os próprios moradores locais levantaram as ações para que o município se desenvolva turisticamente. Para eles e para o grupo do Projeto Rondon, é necessário organizar o Município com ações que promovam a própria comunidade local.

Algumas cidades próximas a Paraíso do Sul já recebem visitantes e a união entre essas cidades por meio de redes de relações, podem auxiliar no desenvolvimento turístico daquela região. É necessária a articulação entre essas cidades rompendo com métodos políticos-administrativos, estabelecendo uma nova forma de governança como nos alerta Veiga (2002).

É necessário fortalecer a Colônia Santo Ângelo e por meio de uma aproximação entre essa e a Quarta Colônia, promover a integração para o fortalecimento regional tendo como principal tema para o turismo, a colonização e o meio rural.

O desenvolvimento turístico só ocorrerá por meio do planejamento e organização interna do Município com cursos de qualificação e de programas de valorização da propriedade rural, visto que as mesmas estão tendo dificuldades devido à atividade de fumo na região. 


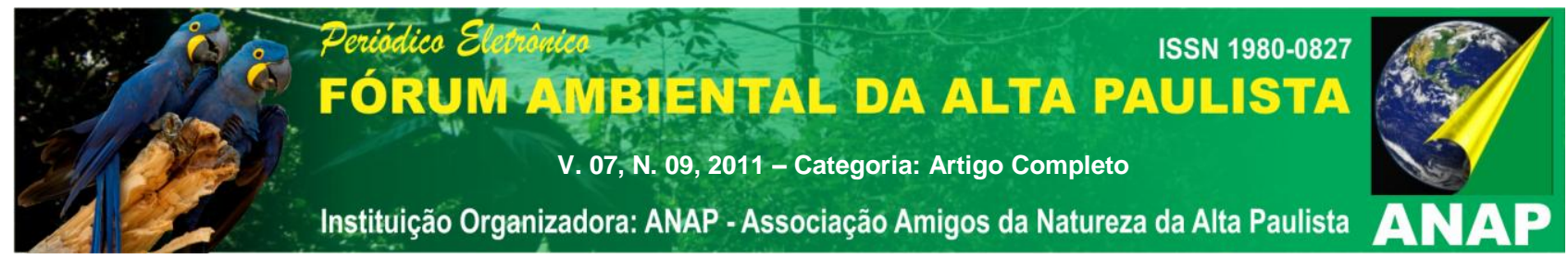

A implantação de atividades como agroecologia, psicultura, agroindústria, fruticultura, por exemplo, podem auxiliar o Município no desenvolvimento do turismo, já que, além de servirem como fontes de renda, essas atividades, favorecem a inserção de outra, o turismo rural, complementando a renda do produtor rural.

\section{REFERÊNCIAS}

DENARDIN, V. F.; SULZBACH, M. T. Produtos com Identidade Territorial: O Caso da Farinha de Mandioca no Litoral Paranaense. In SAQUET, M. A.; SANTOS, R. A.(orgs.) Geografia Agrária, território e desenvolvimento. São Paulo: Expressão Popular, 2010.

HAESBAERT, R. Territórios Alternativos. São Paulo, CONTEXTO: 2002.

LIMONAD, E.; HAESBAERT, R. O Território em Tempos de Globalização. Revista Eletrônica de Ciências Sociais Aplicadas e outras coisas. http: //www.uff.br/etc. 15 de Agosto de 2007, $\mathrm{n}^{\circ} 2$ (4), vol. 1

RUSCHMANN, D. O Turismo Rural e o Desenvolvimento Sustentável. In ALMEIDA, J. A.; FROEHLICH, J. M.; RIEDL, M. Turismo Rural e Desenvolvimento Sustentável. Campinas, SP: Papirus, 2000.

VEIGA, J. E. Cidades Imaginárias: O Brasil é Menos Urbano do que se Calcula. Campinas, SP: Autores Associados, 2002.

WARNIER, Jean - Pierre. A Mundialização da Cultura, Bauru: EDUSC, 2000.

PREFEITURA MUNICIPAL DE PARAÍSO DO SUL-RS. Disponível em. http://www.paraisodosul.rs.gov.br/ acesso em 17 de agosto de 2011.

PROGRAMA NACIONAL DE MUNICIPALIZAÇÃO DO TURISMO. Disponível em http://www.abrasil.gov.br/avalppa/RelAvalPPA2002/content/av_prog/083/prog083.htm acesso em 22 de agosto de 2011.

PROJETO RONDON. Disponível em www.projetorondon.org.br/ acesso em 19 de agosto de 2011.

INVENTÁRIO TURÍSTICO Disponível em http://www.inventario.turismo.gov.br/invtur/jsp/sobre_invtur/ acesso em 22 de agosto de 2011. 